\title{
A IMPORTÂNCIA DA PESOUISA COMO INSTRUMENTO DE GERAÇÃO DE CONHECIMENTO
}

A recente divulgação da pesquisa "Perfil da Enfermagem no Brasil", realizada pelo Cofen em parceria com a Fiocruz e com o apoio de diversos organismos, entidades e associações, permite profunda reflexão sobre a enfermagem e seus atores, assim como constitui tecnologia leve-dura ou imaterial - o saber.

A pesquisa, como produtora de saber, que se estrutura como conhecimento científico e constrói a ciência, é um produto social imbuído de historicidade. Como geradora de conhecimento científico, é tecnologia qualificadora da prática de enfermagem, concretizada nos diferentes fazeres, ou seja, assistência, gerência e ensino(1). Para tanto, o saber gerado deverá ser divulgado, socializado e incorporado à prática da enfermagem, para permitir a transformação da realidade de trabalho de enfermagem e contribuir com a construção da sua ação social.

A pesquisa gera conhecimento importante, por exemplo, sobre as condições de trabalho dos trabalhadores de enfermagem ${ }^{(2)}$, o que dá visibilidade a essa importante problemática no cenário nacional e impõe desafios a serem assumidos pelos gestores de diferentes níveis, assim como pelos organismos, entidades e associações responsáveis pela promoção da saúde desses trabalhadores. Seus resultados apontam um salário não condizente com o trabalho realizado, uma jornada de trabalho excessiva para muitos trabalhadores, vínculos precários e o desemprego. Essas condições, ao mesmo tempo, são causa e consequência da escassez numérica de trabalhadores, que promove o adoecimento desses trabalhadores e compromete a assistência aos pacientes.

Os dados da pesquisa(2) mostram que, no cenário em o trabalho de enfermagem se realiza, estão presentes violência com os trabalhadores, sendo a grande maioria psicológica; a discriminação pelo gênero e os processos desgastantes; a frequente ocorrência de acidentes de trabalho e de problemas de saúde que demandam atendimento médico e afastamentos das atividades. Mesmo diante desse contexto,

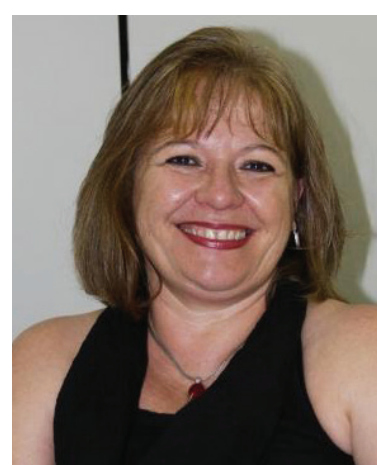

Vanda Elisa Andres Felli

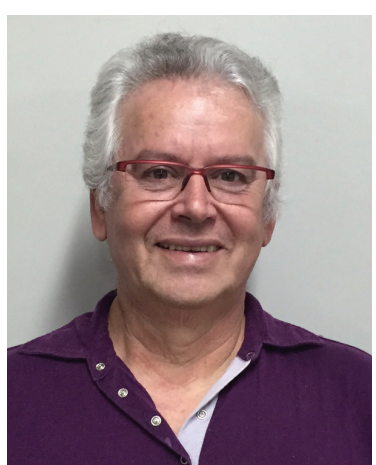

Joel Rolim Mancia os trabalhadores de enfermagem mostram-se desarticulados politicamente, no sentido de buscar estratégias coletivas para a preservação e promoção da sua saúde. Esse quadro mostra a gravidade do quadro de saúde desses trabalhadores, o que compromete a qualidade de assistência da clientela, seja hospitalar ou não. Vários estudos têm abordado essa relação, evidenciando, por exemplo, que o número elevado de pacientes por enfermeiros leva a altas taxas de esgotamento profissional e eleva a taxa de mortalidade dos pacientes ${ }^{(3)}$

Assim, a pesquisa mostra um perfil desfavorável dos trabalhadores de enfermagem em várias dimensões, como a formação, mercado, condições de trabalho e participação sociopolítica. Esses resultados constituem um conhecimento que demanda por instituição de políticas, específicas para os trabalhadores de enfermagem em formação ou já inseridos no mercado de trabalho e em todas as dimensões analisadas.

Referências

1.Merhy EE, Feuerwerker LC. Novo olhar sobre as tecnologias de saúde: uma necessidade contemporânea. Disponivel em http://www.uff.br/saudecoletiva/ professores/merhy/capitulos-25.pdf, Acessado em: 11/03/2016.

2.Enfermagem em Foco. 2016; V.7, n.especial, março 2016. Brasilia: Cofen, 2016.

3.Aiken LH, Clarke SP, Sloane DM, Lake ET, Cheney T. Effects of hospital care environment on patient mortality and nurse outcomes. $J$ Nurs Adm. 2008;38(5):223-9. 